NBER WORKING PAPER SERIES

\title{
ASSESSING THE IMPACTS OF THE PRESCRIPTION DRUG USER FEE ACTS (PDUFA) ON THE FDA APPROVAL PROCESS
}

\author{
Ernst R. Berndt \\ Adrian H. B. Gottschalk \\ Tomas Philipson \\ Matthew W. Strobeck \\ Working Paper 10822 \\ http://www.nber.org/papers/w10822 \\ NATIONAL BUREAU OF ECONOMIC RESEARCH \\ 1050 Massachusetts Avenue \\ Cambridge, MA 02138 \\ October 2004
}

The research reported here constituted a portion of the S.M. theses of Adrian Gottschalk [2004] and Matthew Strobeck [2004]. When this research was undertaken, Tomas Philipson was on leave from the University of Chicago to the U.S. Food and Drug Administration as Senior Economic Advisor to the Commissioner. Research support to Berndt, Gottschalk and Strobeck from general funds at the Harvard-MIT Division of Health Sciences and Technology is gratefully acknowledged, as is data support from the FDA. We thank Ed Hass of the FDA and Roy Gross, MIT, for their very significant assistance throughout this project, and Joseph DiMasi for references and insights. The views and opinions expressed in this paper are those of the authors, and do not necessarily reflect any official position or policy of the institutions with which they are or have been affiliated. The views expressed herein are those of the author(s) and not necessarily those of the National Bureau of Economic Research.

(C)2004 by Ernst R. Berndt, Adrian H. B. Gottschalk, Tomas Philipson, and Matthew W. Strobeck. All rights reserved. Short sections of text, not to exceed two paragraphs, may be quoted without explicit permission provided that full credit, including () notice, is given to the source. 
Assessing the Impacts of the Prescription Drug User Fee Acts (PDUFA) on the

FDA Approval Process

Ernst R. Berndt, Adrian H. B. Gottschalk, Tomas Philipson, and Matthew W. Strobeck

NBER Working Paper No. 10822

October 2004

JEL No. I18, K23, L65

\begin{abstract}
$\underline{\text { ABSTRACT }}$
Congress enacted and renewed the Prescription Drug User Fee Acts (PDUFA) in 1992, and renewed it in 1997 and 2002, mandating FDA performance goals in reviewing and acting on drug applications within specified time periods. In turn, the FDA was permitted to levy user fees on drug sponsors submitting applications to the FDA. While PDUFA mandated action or review times, its ultimate impacts on actual final drug approval times are unknown. We model and quantify the impact of PDUFA-I and II on drug approval times, since these approval dates are the ones most directly related to new medicines becoming available to benefit patients.

In assessing the impacts of PDUFA on drug approval times, it is noteworthy that approval times were trending downwards at $1.7 \%$ percent per year prior to implementation of PDUFA. Assuming continuation of that time trend, approval times post-PDUFA would have fallen even in the absence of PDUFA. Our principal finding is that PDUFA accelerated this downward trend so that instead of a counterfactual 6\% reduction in approval times from 24.2 to 20.4 months in absence of these acts between 1991 and 2002, there was an observed decline of about 42\%, from 24.2 to 14.2 months, following implementation of PDUFA. Thus, of the total observed decline in approval times between 1991 and 2002, approximately two-thirds can be attributed to PDUFA. However, much of this impact occurred in the initial years between 1992 and 1997 (PDUFA-I) rather than during the subsequent 1997-2002 time frame (PDUFA-II). We discuss implications of these findings and how future research might quantify the social value of the observed acceleration in the FDA drug approvals.
\end{abstract}

Ernst R. Berndt

Sloan School of Management

MIT, E52-452

50 Memorial Drive

Cambridge, MA 02142

and NBER

eberndt@mit.edu
Adrian H. B. Gottschalk

agottschalk@sloan.mit.edu

Tomas Philipson

tphilipson@uchicago.edu

Matthew W. Strobeck

mstrobec@mit.edu 


\section{INTRODUCTION}

In virtually all developed countries, regulatory authorities provide public oversight of the safety and efficacy of prescription drugs, prior to their being approved for marketing. In the U.S., such oversight is directed by the Food and Drug Administration ("FDA"). The FDA's mission statement declares that:

"The FDA is responsible for protecting the public health by assuring the safety, efficacy and security of human and veterinary drugs, biological products, medical devices... The FDA is also responsible for advancing the public health by helping to speed innovations that make medicines and foods more effective, safer, and more affordable; and helping the public get the accurate, science-based information they need to use medicines and food to protect their health". ${ }^{1}$

A central tradeoff facing the FDA involves balancing its two goals - protecting public health by assuring the safety and efficacy of drugs, and advancing the public health by helping to secure and speed access to new innovations. Although little quantitative evidence has been produced on this central tradeoff, some observers have argued that the FDA is not taking enough time evaluating new drugs and biologics, while others have argued that the agency is taking too long in doing so. ${ }^{2}$ Little empirical evidence has been put forward to make the case that the FDA is too slow or too fast in its drug approval process, partly due to significant difficulties in measuring the costs and benefits of greater speed. 
In this paper, we report initial results of a multi-stage research project attempting to evaluate empirically and quantitatively the impacts associated with a particular piece of legislation affecting this tradeoff; namely, the Prescription Drug User Fee Act ("PDUFA") passed by Congress in 1992, later continued as PDUFA-II in 1997 and PUDFA-III in 2002. The paper assesses the degree to which these legislative acts affected drug approval times. The paper is part of a larger project focused on quantifying as best as possible the societal costs and benefits of PDUFA in particular, and of policies affecting the speed of new medicine approvals in general. ${ }^{3}$

PDUFA specified performance goals for the FDA in the form of reduced review times, while levying user fees on the industry in terms of payments required for consideration of new drug applications ("NDAs"), new biologic license applications ("BLAs"), and supplemental applications, as well as annual fees for existing manufacturing establishments and products. Between fiscal years 1993 and 2002, net annual collections from PDUFA to the FDA grew more than five-fold, from $\$ 28.5$ million to $\$ 149.1$ million. These user fee revenues represent a substantial portion of the FDA's total revenues obligated to processing human drug applications. For example, in 2002, of the $\$ 347.6$ million total in human drug application processing costs, \$161.8 million (47\%) were covered by user fee revenues, while the remaining \$185.8 million (53\%) came from Congressional appropriations. ${ }^{4}$

We employ data on 662 drug approvals prior to and following enactment of PDUFA (from years 1979 through 2004). Using multivariate regression analysis, we attempt to isolate empirically the incremental impact of PDUFA-I and PDUFA-II on affecting NDA/BLA approval times, over and above that which was trending downwards already prior to the enactment of PDUFA. For each of the 662 drug approvals, we then simulate a counterfactual world and 
predict what approval times would have been in the absence of PDUFA. Our major finding is that PDUFA reduced approval times by about $7.6 \%$ per year during PDUFA-I and about 3.6\% a year during PDUFA-II. Since drug approval times were trending downward at about $1.7 \%$ percent per year even before PDUFA, assuming continuation of this time trend, they would have been lowered even in the absence of PDUFA. PDUFA therefore accelerated this trend; between 1992 and 2002, instead of a counterfactual 6\% reduction in approval times from 24.2 to 20.4 months in the absence of these acts, there was an observed decline of about $42 \%$, from 24.2 to 14.2 months, with PDUFA. Thus of the total observed decline in approval times, approximately two-thirds can be attributed to PDUFA. However, much of this impact occurred in the initial years between 1992 and 1997 (PDUFA-I) rather than during the subsequent 1997-2002 time frame (PDUFA-II).

It is important to note that our results concern approval times, as opposed to the performance goals of PDUFA which focused on action or review times of the agency in handling applications. The former is what matters for consumer welfare, but the latter is what the agency can control. For example, PDUFA stipulated a goal that the $90^{\text {th }}$ percentile of the review time of standard applications was to be 12 months, while the $90^{\text {th }}$ percentile of the approval time in our data was 42 and 36 months for PDUFA-I and PDUFA-II respectively. It therefore appears that while FDA review times of the agency may have been fully met under PDUFA, the approval times are lagging considerably behind PDUFA goals on review times.

The remainder of this paper proceeds as follows. In Section II we provide a brief introduction and overview of PDUFA-I and PDUFA-II. In Section III we discuss the difference in observed review and approval times pre- and post-PDUFA. Then in Section IV we consider various specifications relating FDA approval times to a number of explanatory variables, 
including PDUFA and other covariates. In Section V we present empirical results. Finally, in Section VI we summarize our findings, note limitations of our research, and suggest directions for further research.

\section{II. $\quad$ THE PRESCRIPTION DRUG USER FEE ACTS (PDUFA)}

The concept of payment of user fees by individuals or firms being provided services by a government regulatory body has ample precedent, e.g., application submission fees to the U.S. Patent and Trademark Office. The development of the Prescription Drug User Fee Act permitted the FDA to collect fees from sponsors submitting an NDA or BLA for review. The passage of PDUFA-I in 1992 was, however, somewhat controversial in that the amount of fees collected for each sponsor application was very substantial, unlike that for patent applications. In the initial fiscal year 1993 user fee schedule, applications with clinical data were assessed a one-time fee of $\$ 100,000$; each supplemental application with clinical data, and applications with no clinical data, \$50,000; annual manufacturing establishment fees were $\$ 36,080$, and annual product fees were \$6,000. With effective renewals of PDUFA-I in 1997 under the Food and Drug Modernization Act of 1997 (“PDUFA-II”) and the Bioterrorism Preparedness and Response Act of 2002 (“PDUFA-III”), fees have escalated sharply. In fiscal year 2004, for example, applications with clinical data are assessed a one-time fee of $\$ 573,500$; each supplemental application with clinical data, and applications with no clinical data, are assessed a user fee of $\$ 286,750$; annual manufacturing establishment fees are $\$ 226,800$, and annual product fees are $\$ 6,000$. Waivers and exemptions are granted to small firms, and to sponsors submitting an application under the Orphan Drug Act of $1983 .^{5}$ 
In exchange for the collected user fees, the FDA is legally obliged to "review and act on" NBA/BLA submissions. However, reviewing and acting on is not the same as reaching a final approve/do not approve decision. According to the PDUFA-III legislation, for example:

"'review and act on' is understood to mean the issuance of a complete action letter after the complete review of a filed complete application. The action letter, if it is not an approval, will set forth in detail the specific deficiencies and, where appropriate, the actions necessary to place the application in condition for approval.",6

In essence, therefore, PDUFA mandates responses and action letters from the FDA, but not necessarily final approvals or denials.

NDA/BLA submissions are assigned either a "standard" or "priority" status, depending in part on the novelty of the therapeutic and the existence of unmet needs. In the case of PDUFA-I, II and III, the FDA is required to deliver a "complete review" on $90 \%$ of priority applications within six months. For standard applications, the FDA was expected to review $90 \%$ of applications in twelve months under PDUFA-I; currently, the FDA is expected to review $90 \%$ of standard applications in ten months.

On the action date mandated by PDUFA, the FDA issues one of three actions. The first action is a non-approvable letter indicating that the NDA/BLA has not satisfied the FDA's standards for safety and/or efficacy. The second type of action is an "approvable" letter that indicates the NDA/BLA can be approved if certain deficiencies and questions are appropriately acted upon by the sponsor. The third type of action is the ultimate approval letter that gives the sponsor company the right to market the drug to the public. 
Researchers such as Peltzman [1974], Olson [1997,1998,2004] and Carpenter [2002] have long argued that personnel at the FDA are considerably more worried about committing Type 1 errors (approving a drug that is unsafe and/or lacks efficacy) than Type 2 errors (not approving a safe and effective drug). ${ }^{7}$ Given the costs and punishments that can be meted out by Congress for Type 1 errors, it is not surprising that many observers believe that Type 1 errors have received disproportionate attention. While the costs of delaying life-saving and quality of life-improving medications are real and impose pain and suffering on patients seeking new medicines, these costs from Type 2 errors are not nearly as visible as the Type 1 errors. Rather than mandate specific remedies that would attempt to deal more directly with Type II errors, Congress has attempted to provide incentives for improved efficiencies at the FDA; PDUFA may be viewed as an example of such incentives.

\section{REVIEW vs. APPROVAL TIMES UNDER PDUFA}

Although PDUFA action date mandates have generally been met by the FDA, these action dates are not the same as approval dates, the latter being the time at which a drug is approved for marketing in the US. There is a strong analogy between this process and the academic publishing process; action dates correspond to reject or revise-and-resubmit dates and approval dates correspond with ultimate acceptance/rejection dates. The approval dates are what ultimately affects consumer welfare as it is only after marketing approval is granted that consumption can take place. ${ }^{8}$ The question then arises to what degree the increased performance in review times and action dates has translated into better performance for approval times.

Because the mandates of PDUFA proposed upper bounds on the percentiles of action times, it is instructive to display drug approval data employing survival curves that plot the proportion of approvals not yet approved within a fixed time period. More precisely, Figures 1 
and 2 survival curves plot the percent approvals remaining over time in months, during different time periods. As the time scale increases along the horizontal axis in Figures 1 and 2, more NDAs/BLAs are approved, and thus the proportion of approvals remaining declines.

Figure 1 displays the patterns for standard drugs, while Figure 2 provides analogous information for applications granted priority review status; recall that different PDUFA goals applied to these two categories. In each of the two figures, separate survival curves are plotted for the 1979-86, 1987-92, PDUFA-I and PDUFA-II time periods. Survival curves from more recent time periods are clearly separate from and ever closer to the origin than are those from earlier eras. The horizontal line indicates the 90 percent level of survival (10 percent of approvals remaining), since that was the relevant level for several PDUFA-mandated performance goals. The more rapid decline in survival curves during PDUFA-I and II relative to the pre-PDUFA time period indicates faster approvals. In contrast to the PDUFA goals, only $14 \%$ percent of standard drugs were approved at 12 months and $22 \%$ percent of priority drugs were approved at six months under PDUFA-I. The corresponding percentages for PDUFA-II were $20 \%$ and $23.5 \%$. Consequently, although FDA actual review times met the PDUFA goals, the time elapsed until drug applications were granted final approving for marketing was significantly greater than the action/review performance goals.

\section{IV. $\quad$ SPECIFICATIONS TO ASSESS THE IMPACT OF PDUFA ON APPROVAL TIMES}

Drug approval data provided us by the FDA indicate that approval times have been falling for quite some time, at least since 1979, and appear to have accelerated, particularly during PDUFA-I. As seen in Figure 3, mean approval time during 1979-86 was 33.57 months, 28.19 months in 1987-92, 18.61 months during PDUFA-I, and 16.09 months in PDUFA-II. Since the approval time data is skewed to the right, the corresponding median approval times are 
all smaller, but they too fall over time: 27.07 (1979-86), 23.83 (1987-92), 15.18 (PDUFA-I), and

\subsection{7 (PDUFA-II).}

Although there is general agreement that PDUFA has lowered approval review times, given the presence of confounding factors, the quantitative magnitude by which it has done so has not been established. ${ }^{9}$ In estimating the magnitude attributable to PDUFA, as was noted above, it is important to note that approval times were already trending downwards prior to PDUFA-I, so that simply calculating pre- and post-PDUFA approval times would overstate the magnitude of the impact of PDUFA. Moreover, in response to patient advocacy groups highlighting the need for more rapid approval of drugs that treat certain life-threatening illnesses such as AIDS, the FDA has assigned these NDAs a disproportionately high priority status. To isolate the impact of PDUFA on FDA approval times, it is imperative that changes over time in the composition among therapeutic classes of the NDAs be taken into account, as well as other changes over time that could have affected approval times.

We specify a multivariate linear regression model with the logarithm of the time between NDA/BLA filing and NDA/BLA approval in months (LNAPP) as the dependent variable. We hypothesize that LNAPP is related to a number of explanatory variables, including the following. We construct a TIME TREND variable as a time counter equal to 1 during fiscal year 1980 (10/01/1979 to $9 / 30 / 1980)$, equal to 2 during fiscal year $1981(10 / 01 / 1980$ to $9 / 30 / 1981)$, and so forth, up to 23 in fiscal year 2002 (10/01/2001 to 9/30/2002); each observation is assigned a TIME TREND value given the date the NDA/BLA was filed with the FDA (not the date it was approved). We expect the coefficient on TIME TREND to be negative, reflecting shorter review/approval times in more recent years. 
In order to assess whether the decline in approval times has been accelerating or decelerating in the last decade, we also construct two interaction variables. First, in addition to the TIME TREND variable, we construct a variable TIME that counts years during the PDUFA eras: TIME equals 1 if the NDA/BLA was filed in the first year (actually, 13 months) during PDUFA-I (9/1/92 through 9/30/93), 2 if it was filed between 10/1/93 and 9/30/94, and so on, up to 10 if the NDA/BLA was filed between 10/1/2001 and 9/30/2002 (the last year of PDUFA-II). PDUFA-I*TIME is then constructed as the product of TIME and a 0-1 indicator variable PDUFA-I that takes on the value one if the NDA/BLA was filed during PDUFA-I (9/1/1992 through 9/30/1997), else PDUFA-I is zero. The interaction variable PDUFA-II*TIME is constructed analogously.

With these variables of primary interest, and denoting other covariates by $\mathrm{X}_{\mathrm{i}}$, we specify a regression equation for the $\mathrm{i}^{\text {th }}$ observation as follows:

$$
\begin{aligned}
\text { LNAPP }_{\mathrm{i}} & =\beta_{0}+\beta_{1} * \text { TIMETREND }_{\mathrm{i}}+\beta_{2} * \text { PDUFA-I*TIME }_{\mathrm{i}} \\
& +\beta_{3} * \text { PDUFA-II*TIME } \\
\mathrm{i} & +\mathrm{X}_{\mathrm{i}} \beta+\varepsilon_{\mathrm{i}}, \quad \mathrm{i}=1, \ldots, \mathrm{I}, \quad \text { (Eqn. 1) }
\end{aligned}
$$

where $\varepsilon_{\mathrm{i}}$ is an independently and identically normally distributed random disturbance term, and the $\beta$ 's are parameters to be estimated. Note that in this specification, parameter estimates on the interaction variables represent any differential annual impact of the passage of time on LNAPP during the PDUFA eras, relative to that existing over the entire 1979-2002 time period.

Negative (positive) parameter estimates on these interaction variables are interpreted as an acceleration (deceleration) of the decline in approval times during the PDUFA years. If approval times were not significantly different during the PDUFA eras relative to pre-PDUFA, then $\beta_{2}=$ $\beta_{3}=0$. If the annual differential impact of the passage of time on LNAPP was the same during PDUFA-I and PDUFA-II, then $\beta_{2}=\beta_{3}$. 
A number of potentially confounding covariates are also included among the regressors in X. ${ }^{10}$ Three 0-1 indicator variables include: ORPHAN (1 if the application was filed citing eligibility under the 1983 Orphan Drug Act, else 0); PRIORITY (1 if the application was assigned priority status by the FDA after 1991, or an A or B rating prior to 1991, else 0); and DOMESTIC (if the application sponsor was headquartered inside the US, else 0). We expect the coefficient on PRIORITY to be negative. Although it is reasonable to expect the coefficient on ORPHAN to be negative as well, since about $60 \%$ of the ORPHAN drug applications were assigned PRIORITY status, multicollinearity between these two variables may confound the expected association. Finally, to the extent DOMESTIC applicants have greater familiarity and cumulative experience with the FDA, we might expect the sign of the coefficient on DOMESTIC to be negative.

It is plausible that review times vary across therapeutic classes, due to inherent differences across diseases and therapies. To accommodate this possibility, we construct 0-1 indicator variables assigning each observed NDA/BLA approval to one and only one of the following 13 therapeutic classes: AIDS, ANTI-INFEC (anti-infective), ANTI-INFLAM (antiinflammatory), BIOLOGIC (involving a Biologic License Application, rather than an NDA), CARDIO (cardiovascular or renal), CNS (central nervous system), DERM-OPTHAL (dermatologic or ophthalmologic), GI (gastrointestinal), METABOL-ENDO (metabolic or endocrine), NEOPLASTIC (oncologic), RADIO-DIAG (radiopharmaceutical or diagnostic), RESPIRATORY, and a miscellaneous OTHER category. Roughly speaking, this classification corresponds with the various division review structures at the Center for Drug Evaluation Research and the Center for Biologic Evaluation Research at the FDA existing up through 2002. 
In the regression results reported below, the BIOLOGICS class variable is omitted, and thus this serves as the reference class.

It is possible that in addition to variations across therapeutic classes, the complexity of certain sponsor development efforts affected review times at the FDA. For 621 of the 662 NDA/BLA approvals in the data base, we have also obtained information on the date at which the initial IND for that therapeutic was filed with the FDA. We construct the variable LNINDNDA as the logarithm of the time in months between the filing of the IND and the filing of the NDA/BLA. A priori, the sign of the coefficient on LNINDNDA is ambiguous. If a more thorough drug development process prior to the filing of the NDA/BLA provides the FDA with additional useful information, facilitating a more expeditious subsequent FDA review, then the coefficient LNINDNDA would be negative. On the other hand, if the longer development time in between the IND and the NDA/BLA filing reflects inherent difficulties and complexities of the clinical development process for that drug, it may also take longer for the FDA to diligently review the application; in such a case, the coefficient on LNINDNDA would be positive.

There are instances in which a sponsor has never filed an IND with the FDA (this phase may have been carried out overseas), and in other cases the IND date data are simply missing; altogether, 41 of the 662 observations have missing IND date data. To allow for the possibility that these 41 observations missing IND dates are non-random or non-representative, we construct and include as a regressor a 0-1 indicator variable IND MISS that equals 1 if the observation has a missing IND value, else it is zero.

A rather different factor potentially affecting NDA/BLA approval times involves the presence or absence of top leadership at the FDA. ${ }^{11}$ To address the issue of whether the presence or absence of a Congressionally-confirmed FDA Commissioner has impacted the speed of 
NDA/BLA approval times, we consider several alternative specifications that in different ways attempt to quantify the absence of a confirmed Commissioner.

Historically, between 1979 and 2002, six Commissioner vacancy periods occurred: June 30, 1979 to October 21, 1979 (113 days); January 20, 1981 to April 13, 1981 (83 days); September 11, 1983 to July 15, 1984 (308 days); December 17, 1989 to November 7, 1990 (325 days); February 28, 1997 to November 30, 1998 (640 days); and January 19, 2001 to November 14, 2002 (664 days). Note that the first two vacancy periods lasted less than four months, the second two between 10 and 11 months, and the last two more than 20 months. Thus, the longest Commissioner vacancies occurred during PDUFA-II, even as the FDA was implementing measures to reduce approval times. ${ }^{12}$ This suggests that it may be difficult to disentangle the effects of PDUFA from those possibly due to the absence of a confirmed Commissioner.

In terms of quantification of vacancy prevalence, for each NDA/BLA, we first calculate the overlap in time period of the vacancy of a Commissioner with the time period during which the application was being reviewed at the FDA. The variable NOCOM\% is then computed as the ratio of Commissioner absent days to days that particular NDA/BLA was under review before approval. We consider several alternative specifications to the "base case" in Eqn. (1) above. In Model I NOCOM\% appears as an additional regressor relative to the base case specification. In Model II, the logarithm of NOCOM\%, denoted LNNOCOM, is added instead as a regressor. In those instances in which NOCOM\% is zero, we arbitrarily overrule it and instead assigned LNNOCOM a value of LOG(0.001). In Model III, a simple and coarse 0-1 indicator variable EVERNOCOM is added instead, taking on the value 1 if NOCOM\% $>0$, else EVERNOCOM $=0$. In this specification, the mere occurrence anytime during the approval process of a non-confirmed Commissioner is hypothesized to affect approval time. Finally, in 
Model IV a 0-1 indicator variable NOABSENCE is first defined as being equal to 1 if NOCOM $\%=0$, else NOABSENCE equals zero. Then another variable, called LNNOCOMX, is constructed as being equal to LNNOCOM whenever NOCOM $\%>0$, else LNNOCOMX $=0$. In Model IV both NOABSENCE and LNNOCOMX are included as regressors.

If the absence of a confirmed Commissioner increased regulatory delays and approval times at the FDA, other things equal, then one would expect the coefficient estimates on NOCOM\%, LNNOCOM and EVERNOCOM to be positive in Models I, II and III, respectively. In the case of Model IV, while the parameter on NOABSENCE would be expected to be negative, that on LNNOCOMX would be positive. Of course, expected coefficient signs would be reversed if it were hypothesized that the absence of a confirmed Commissioner reduced FDA approval times, other things equal.

Finally, for purposes of comparison with time at the FDA prior to NDA/BLA approval, we also consider a specification in which we examine factors affecting the clinical development time between the sponsor's filing of the IND and the submission of the NDA/BLA. As has been noted by a number of observers, this time interval is typically two to four times larger than FDA review time prior to approval. ${ }^{13}$ For this pre-NDA/BLA clinical development time analysis, we specify the same set of regressors as in the LNAPP regression, except now of course LNINDNDA becomes the dependent variable, and those 41 observations for which IND MISS = 1 must be deleted. We hypothesize that in this pre-NDA/BLA clinical development time regression, the TIME TREND coefficient is non-negative (either zero or positive), as is that on the PDUFA-I*TIME and PDUFA-II*TIME interaction variables. 


\section{DATA SOURCES AND EMPIRICAL RESULTS}

We now report on data sources, and on results obtained from the multivariate regression analyses. We begin with data sources.

\section{A. Data Sources}

Data on new molecular entities filed at the FDA between 1965 and 2003 were provided us by Ed Hass, Office of Policy and Planning, US Food and Drug Administration. Data fields included NME name (along with any withdrawal information), descriptive characteristics of the drug (whether NDA or BLA, vaccine, diagnostic, radiopharmaceutical, orphan drug, and nuclear related therapeutic); the developing company; developing country; FDA approval date; therapeutic significance rating (A,B,C prior to 1991; priority or standard thereafter); year of first world marketing; country of first world marketing; US trade name at time of approval; IND submission date; NDA/BLA clock date; IND number; elapsed approval time in months; years in the IND phase; total development years; NDA/BLA number; name of the sponsoring company; US/foreign developer code; orphan drug code; and US first marketing date. Additional data include 7-digit and 3-digit therapeutic class codes for each NME. FDA officials believe that these data series are error free and complete from the period of 1975 forward in regards to NDA/BLA approval length.

For purposes of our analysis, we considered all NDA/BLA filed at the FDA beginning with fiscal year 1980 (October 1, 1979 through September 30, 1980) up through fiscal year 2002 (October 1, 2001 through September 30, 2002). This yielded 649 observations, 321 of them being from the pre-PDUFA era up through August 31, 1992, and 328 of them in PDUFA-I or PDUFA-II. Of these, 123 were missing data on therapeutic class codes. A research assistant entered class code data for these products, using information from the 2003 Physicians' Desk 
Reference. To mitigate problems of right-censoring for submissions filed but not yet approved by April 2003 (when the FDA data set was last updated), in May 2004 we augmented the FDA data by adding 13 additional FDA approvals from April 2003 up through May 1, 2004. This yielded a total of 662 observations, 321 pre-PDUFA, and 341 post- PDUFA. Of these, $42.7 \%$ had domestic sponsors, $18 \%$ were orphan drug applications, and $30 \%$ were granted priority review status.

\section{B. Multivariate Regression Empirical Estimates}

The principal empirical estimates from our regression analyses are presented in Table 1. Parameter estimates with p-values less than 0.05 are highlighted in bold. Here we restrict our discussion to general findings. Results concerning therapeutic class-specific impacts are discussed in a separate paper. ${ }^{14}$

Before discussing PDUFA-related findings, we first comment on the impacts of various covariates. The coefficient estimate on LNINDNDA is virtually zero and statistically insignificant, implying that apparently there is no spillover between the time spent in clinical development by the sponsor and the approval time at the FDA. The coefficient estimate on IND MISS is also insignificant, suggesting that the observations missing the IND date are unlikely to be unrepresentative of the larger sample. NDAs/BLAs assigned PRIORITY status, other things equal, have a review time only $61 \%$ (exponentiation of -0.4902) as long as those applications assigned STANDARD review status. This difference is statistically significant. By contrast, drugs having an ORPHAN status and those sponsored by a DOMESTIC applicant have no significant impact on approval time. Recall that the majority of ORPHAN drugs also were assigned PRIORITY status; while the Orphan Drug Act provided incentives to develop drugs targeted at very small populations, the enabling legislation did not accord these drugs any special 
accelerated review status. Having an ORPHAN drug designation in addition to PRIORITY status, therefore, does not appear to have affected approval times significantly.

We now turn to a discussion of PDUFA-related impacts on approval times. As seen near the top of Table 1, the coefficient estimate on TIME TREND is -0.017 , indicating that approval times were declining about $1.7 \%$ annually, ceteris paribus, even in the absence of PDUFA; this estimate is statistically significant (p-value 0.038). Declines in approval time accelerated significantly, however, during the PDUFA-I years, with a differential decline from the overall trend of about $-7.6 \%$ annually. Hence, during the PDUFA-I era, approval times declined more than $9 \%$ annually $(1.7 \%+7.6 \%=9.3 \%)$, significantly greater than the $-1.7 \%$ during the prePDUFA-I era.

While declines in approval time continued during PDUFA-II, the declines were smaller than during PDUFA-I. As seen in Table 1, relative to the pre-PDUFA time period, approval times for NDAs/BLAs submitted during PDUFA-II declined about 3.6\% more rapidly, not as dramatic a differential as during PDUFA-I, but still significant and meaningful, especially when cumulated over time. This pattern of greater acceleration in shortened approval times during PDUFA-I than during PDUFA-II is consistent with the notion that during PDUFA-I "low hanging fruit" procedures were implemented initially, which had a very significant impact on reducing approval times. While subsequent efforts by the FDA continued to result in reductions in approval times during PDUFA-II, these efforts yielded smaller annual increments, in part reflecting the fact that significant improvements had already been achieved.

One way of envisioning the implications of these PDUFA-related findings is to create a counterfactual situation in which there is no PDUFA, i.e., one in which the PDUFA-I*TIME and PDUFA-II*TIME variables are set to zero, only the TIME TREND variable changes over time, 
and all other regressors are evaluated at their overall sample means. ${ }^{15}$ The time trend of predicted approval times from this base case regression equation, with and without the PDUFA variables, is plotted in Figure 4.

As seen in Figure 4, had PDUFA-I and PDUFA-II not been implemented, between 1991 and 2002 average approval times would have fallen about $16 \%$ from 24.2 to 20.4 months. Instead, because of PDUFA-I and PDUFA-II, between 1991 and 2002 approval times declined about $42 \%$ to 14.2 months. Of the total 10.1 month decline, therefore, approximately $62 \%$ is due to PDUFA-I and II. Most of this reduction occurred during PDUFA-I. Without PDUFA-I, mean reductions in approval time would have declined from 24.2 in 1991 to 22.3 months in 1997 (a 1.9 month or $8 \%$ reduction), but with PDUFA-I the reduction was much larger to 14.9 months (a 9.3 month or $38 \%$ reduction). Hence, declines in mean approval times between 1991 and 1997 were $80 \%$ due to PDUFA-I, and $20 \%$ to pre-existing trends. However, during PDUFA-II, initially the mean approval time increased from 14.8 in 1997 to 17.6 months in 1998, but after that approval times steadily declined, and by 2002 they had fallen a total of 0.7 months to 14.2 months. Proportionally, the PDUFA-II reduction was smaller at $5 \%$.

As a further assessment of estimated coefficients on the PDUFA-related variables, we tested two hypotheses. The first is that the annual differential reductions in approval times during PDUFA-I were the same as those in PDUFA-II; this corresponds to the null hypothesis that $\beta_{2}=\beta_{3}$. Using an F-test analysis of variance procedure, we reject this hypothesis decisively $\left(\mathrm{F}_{1,641}=8.325\right.$, p-value 0.004). Not surprisingly, then, we also reject the null hypothesis that both these parameters simultaneously equal zero, i.e., that there is no differential impact of the passage of time on average approval times during PDUFA-I and PDUFA-II $\left(\mathrm{F}_{2,641}=5.678\right.$, $\mathrm{p}$ value 0.004$)$. 
The estimated regression equation in Table 1 is based on a number of assumptions. Although the null hypothesis of homoskedasticity of the disturbance terms is rejected (White test procedure, $\mathrm{p}$-value 0.005$)$, heteroskedasticity-consistent standard errors for the coefficients on the TIME TREND, PDUFA-I*TIME and PDUFA-II*TIME variables are virtually identical to those in Table $1-0.008,0.023$ and 0.015 , respectively. ${ }^{16}$ Another assumption is that the coefficients on the variables other than the 0-1 therapeutic class indicator variables are equal across the various therapeutic classes. Using a modified Chow test procedure, we are unable to reject the null hypothesis that these coefficients are equal across classes $\left(\mathrm{F}_{96,545}=1.2157, \mathrm{p}\right.$-value $0.0948) .^{17}$

As noted earlier, for purposes of comparison we have also estimated an auxiliary regression specification in which LNINDNDA - the logarithm of the time in months between the IND and the NDA/BLA filing - is the dependent variable. Results from this pre-NDA/BLA clinical development time regression appear in the final three columns of Table 1. In terms of the impact of PDUFA-related variables on clinical development time, the coefficient on the overall TIME TREND variable is positive and significant, increasing about $2.6 \%$ annually (pvalue 0.015). While the estimated coefficients on PDUFA-I*TIME and PDUFA-II*TIME are negative and of similar magnitude $(-0.0445$ and -0.0423 , respectively), only the latter is statistically significant (p-value 0.039). Since the impact of the passage of time during the PDUFA years is the sum of the estimated coefficients on TIME TREND and PDUFA-II*TIME (e.g., $0.0271-0.0423=-0.0152$ ), the total impact is quite small, and likely statistically insignificant. We conclude that while PDUFA has had a significant impact on reducing drug approval times, it has not had any appreciable impact on clinical development times. 
Our final line of empirical analysis involves an exploratory examination of the impact of the absence of a Congressionally-confirmed FDA Commissioner on approval times, controlling for other confounding variables. Our results are provocative but fragile, and clearly call for more detailed examination. Parameter estimates on the various Commissioner-absence measures in Models I through IV, as well as those on the TIME TREND and PDUFA interaction variables, along with parameters from the "base case" specification in Table 1, are given in Table 2.

In a specification with NOCOM\% (Model I) as an additional regressor, the coefficient estimates is 0.0321 , but with a p-value of 0.710 , it is clearly not significant. Parameter estimates on the TIME TREND and PDUFA interaction variables are not much affected, relative to the base case. It is worth noting that because approval time is in the denominator of NOCOM\% and also appears in log-transformed form as the dependent variable in this specification, one would expect the coefficient estimate on NOCOM\% to reflect a spurious negative correlation, and thus be downward biased.

In Model II, where LNNOCOM is instead the additional regressor (and observations for which NOCOM\% $=0$ are arbitrarily assigned a value of $\log [0.001])$, the coefficient estimate is 0.0591 , with a p-value of $<0.001$. In this specification, the elasticity of approval time with respect to NOCOM\% is positive, but small. Because the log of approval time appears on both the left and right-hand side of the regression specification, again one might expect the coefficient estimate on LNNOCOM to be downward biased. Notice also that in this specification, the TIME TREND coefficient estimate becomes positive and significant, and both PDUFA-related coefficient estimates become much more negative. Recall that the extent of Commissioner absence was much greater during PDUFA-I and especially PDUFA-II than it was earlier -- $61 \%$ of all Commissioner absence days occurred during PDUFA-I and II, while only $39 \%$ took place 
prior to PDUFA. Because in Model II the increased prevalence of Commissioner absences lengthens approval times, the impact of PDUFA on reducing approval times is estimated as being even greater than in the base case.

In Model III, however, where the 0-1 EVERNOCOM indicator variable takes on the value of 1 whenever NOCOM\% > 0 , the positive coefficient estimate becomes much larger at 0.3928 , with a p-value of $<0.001$. In this specification, the mere existence of any absence of the Commissioner while the NDA/BLA is being reviewed increases approval times by about $48 \%$, other things equal. We view this result as rather implausible. Note also that again the estimated coefficients on the TIME TREND and PDUFA interaction variables change considerably from the base case specification, with the PDUFA-related coefficient estimates becoming much larger in absolute value.

Finally, in Model IV, the most complex specification, both NOABSENCE and LNNOCOMX appear as regressors. Here the estimated coefficient on NOABSENCE is negative at -0.2445 (p-value $<0.001$ ), while that on LNNOCOMX is -0.1183 (p-value $<0.001$ ). Although the negative estimate on NOABSENCE is consistent with the hypothesis that Commissioner absence increases approval times, other things equal, the negative estimate on LNNOCOMX is inconsistent with that hypothesis. As in Models II and III, the estimated annual differential impacts of passage of time during the PDUFA-I and PDUFA-II eras are much larger (in absolute value) than in the base case.

Although these various specifications point to the possibility that the extent of Commissioner absence increases drug approval times, other things equal, the magnitude of the estimated impacts are clearly fragile. Informal conversations we have had with officials at the FDA and with industry regulatory affairs personnel reflect considerable skepticism that the 
presence or absence of a confirmed Commissioner would have any substantial impact on day-today application review procedures and other daily review operations, and thus on average approval times. Rather, industry officials suggest that while the Commissioner may become involved in particularly controversial situations, these are likely to be relatively infrequent. ${ }^{18}$ We conclude here that to the extent further analysis of this issue is warranted, there is a clear need to develop more defensible and independent measures of the impact of a confirmed Commissioner on day-to-day operations.

\section{CONCLUDING REMARKS AND FUTURE RESEARCH}

In this paper we have modeled and quantified the impact of PDUFA-I and II on drug approval times at the FDA, in part by constructing a counterfactual hypothetical situation in which PDUFA did not exist. We find that PDUFA-I resulted in an acceleration of the decline in NDA/BLA approval times at the FDA. Of the 10 month decline from about 24 months in 1991 to 14 months in 2002, about $60 \%$ is attributable to the enactment and implementation of PDUFA. Declines in approval time decelerated significantly, however, between PDUFA-I and PDUFA-II, with annual differential declines about half as large during PDUFA-II.

A limitation of our study is that we have not undertaken a separate analysis of "fast track" provisions that involve rolling submissions to the FDA. We believe the impact of this omission is likely to be relatively minor, for not only is the number of NDAs/BLAs granted fast track study in our sample up through 2002 likely to be small, but preliminary analyses by several FDA observers suggests that the differential impact of fast track from priority status on approval times is small, and in some cases fast track may even lengthen approval times. ${ }^{19}$ Research results reported by DiMasi [1997] suggest that fast track approval status had a positive but statistically insignificant impact on drug approval times between 1987 and 1995. 
Our analysis point to a large set of research questions that address a variety of implications from the findings reported here, some of which we are currently investigating and plan to report on in the near future. For example, it will be useful to disaggregate the results on reductions in drug approval times reported here into separate therapeutic classes, to determine in which therapeutic areas reductions were largest.

A second very important set of issues concerns the implied net social benefit of the reduced approval times induced by PDUFA. Although there is debate about the appropriate speed of the FDA approval process, to the best of our knowledge no framework has been put forward to quantitatively assess the costs and benefits of faster approval. This is an important topic for future research. The primary costs in the case of PDUFA would be the additional FDA review resources paid for by PDUFA user fees, and any excess burden imposed through distorted R\&D behavior by those taxes. The principal benefits would consist of the additional present value to consumers who benefit from earlier consumption of the newly approved drugs. Developers would also benefit from being able to plan with greater certainty when their product would need to be manufactured and marketed. Evaluation of the net benefits of PDUFA would not only be useful in the aggregate, but also over the various therapeutic classes.

In evaluating costs and benefits of more rapid drug approvals by the FDA, it would also be necessary to include in the cost calculations the possibility that while PDUFA may have accelerated the approval process, it may also have altered the set of drugs to be approved, lowering the quality of approved drugs. Indeed, some have argued that the FDA, although not mandated to do so by Congress, serves as a principal source of evidence-based medicine and that any legislation that led to compromising the FDA's ability to assess the safety of new medications would entail large social costs. 
To date, there is only limited evidence on whether PDUFA affected the quality of drugs approved by the FDA. A study published by the U.S. Government Accounting Office in 2002 at the time PDUFA-III renewal was being considered reported that from 1985 to $1992,3.10 \%$ (6 of 193) of drugs approved by the FDA were subsequently withdrawn for safety-related reasons, whereas during PDUFA-II between 1993 and 2000 a slightly higher percentage, 3.47\% (9 of 259) were withdrawn for safety reasons. The GAO did not report whether this difference was statistically significant. ${ }^{20}$ In response, the FDA noted not only issues of possible lack of statistical significance given that withdrawals were relatively rare events, but also that the GAO had excluded the increasing number of biologics from their analysis. Moreover, in some cases post-PDUFA FDA approvals were attributed to the PDUFA time frame, when in fact NDAs for those NMEs had been submitted prior to PDUFA-I. According to the FDA's analysis, the withdrawal percentage from 1979 to 1992 was close to $2.5 \%$, while for NDAs/BLAs approved during PDUFA-I and PDUFA-II until 1999, the withdrawal rate was virtually identical at $2.6 \% .^{21}$

A related set of costs would consider whether the proportion of NDAs/BLAs that failed or were withdrawn changed during the PDUFA era. Due to confidentiality obligations to sponsor companies, the FDA was unable to provide detailed or aggregate information on NDAs/BLAs that were rejected or withdrawn. It is possible that failure rates of NDAs/BLAs did not change from the pre-PDUFA time period to the PDUFA era (or that trends in rates did not change). However, if failure rates increased during PDUFA, this added cost would need to be taken into consideration; similarly, a reduction in failure or withdrawal rates would increase the benefits delivered by PDUFA. While lack of data availability precludes a robust analysis of this issue, by itself this issue does not negate the benefits realized from more rapid approvals that actually occurred under PDUFA. 
A third set of issues worthy of further research is an assessment of how PDUFA altered the present values of revenues and costs to developers of the more rapidly approved drugs. More generally, a decomposition of the social surplus resulting from PDUFA into its consumers' surplus and producers' surplus components would be most useful and informative. 


\begin{tabular}{|l|c|c|c|c|c|c|}
\hline \multicolumn{7}{|c|}{ Table 1 } \\
\hline \multicolumn{7}{|c|}{ ECONOMETRIC RESULTS FROM MULTIVARIATE REGRESSIONS } \\
\hline & \multicolumn{2}{|c|}{ Dependent Variable: LNAPP } & \multicolumn{3}{|c|}{$\begin{array}{c}\text { Dependent Variable: } \\
\text { LNINDNDA }\end{array}$} \\
\hline REGRESSOR & Estimate & Std. Err. & $\underline{\text { P-value }}$ & $\frac{\text { Estimate }}{\text { Std. Err. }}$ & P-value \\
\hline Constant & $\mathbf{3 . 5 1 5 3}$ & $\mathbf{0 . 1 5 6}$ & $<\mathbf{0 . 0 0 1}$ & $\mathbf{3 . 5 5 5 9}$ & $\mathbf{0 . 1 4 9}$ & $<\mathbf{0 . 0 0 1}$ \\
\hline LNINDNDA & -0.0014 & 0.031 & 0.965 & NA & NA & NA \\
\hline IND MISS & 0.1032 & 0.160 & 0.521 & NA & NA & NA \\
\hline TIME TREND & $\mathbf{- 0 . 0 1 7 1}$ & $\mathbf{0 . 0 0 8}$ & $\mathbf{0 . 0 3 8}$ & $\mathbf{0 . 0 2 7 1}$ & $\mathbf{0 . 0 1 1}$ & $\mathbf{0 . 0 1 2}$ \\
\hline PDUFA-I*TIME & $\mathbf{- 0 . 0 8 0 7}$ & $\mathbf{0 . 0 2 4}$ & $\mathbf{0 . 0 0 1}$ & -0.0485 & 0.032 & 0.129 \\
\hline PDUFA-II*TIME & $\mathbf{- 0 . 0 3 6 7}$ & $\mathbf{0 . 0 1 5}$ & $\mathbf{0 . 0 1 8}$ & $\mathbf{- 0 . 0 4 4 3}$ & $\mathbf{0 . 0 2 0}$ & $\mathbf{0 . 0 3 0}$ \\
\hline PRIORITY & $\mathbf{- 0 . 4 9 0 2}$ & $\mathbf{0 . 0 5 6}$ & $<\mathbf{0 . 0 0 1}$ & 0.0848 & 0.075 & 0.259 \\
\hline ORPHAN & 0.1088 & 0.065 & 0.094 & 0.0667 & 0.088 & 0.449 \\
\hline DOMESTIC & -0.0718 & 0.045 & 0.114 & -0.0582 & 0.063 & 0.358 \\
\hline & & & & & & \\
\hline N & 662 & & & 621 & & \\
\hline R-squared & 0.3925 & & & 0.0866 & & \\
\hline Eqn. F-statistic & 20.708 & & & 3.170 & & \\
\hline
\end{tabular}

Notes: The reference case is for a NDA/BLA assigned a standard rating, not an ORPHAN drug, sponsored by a non-DOMESTIC applicant. NA is not applicable. Twelve therapeutic drug class dummy variables are included in the specification but their coefficient estimates are not reported. 


\begin{tabular}{|c|c|c|c|c|c|}
\hline & & Table 2 & & & \\
\hline RESUL? & $\begin{array}{r}\text { I ALTERN } \\
\text { SPE }\end{array}$ & $\begin{array}{l}\text { TIVE CO } \\
\text { IFICATIC }\end{array}$ & $\begin{array}{l}\text { MISSION } \\
\text { S }\end{array}$ & R ABSENC & \\
\hline & Errors in $\mathrm{P}$ & entheses, $\mathrm{F}$ & alues in $\mathrm{Br}$ & kets) & \\
\hline Variable & Base Case & Model I & Model II & Model III & Model IV \\
\hline TIMETREND & -0.0171 & $\overline{-0.0166}$ & 0.0020 & 0.0074 & 0.0096 \\
\hline & $(0.008)$ & $(0.008)$ & $(0.008)$ & $(0.008)$ & $(0.008)$ \\
\hline & {$[0.038]$} & [0.049] & [0.811] & {$[0.382]$} & {$[0.254]$} \\
\hline PDUFA-I*TIME & -0.0807 & -0.0843 & -0.1424 & -0.1475 & -0.1337 \\
\hline & $(0.0241)$ & $(0.026)$ & $(0.025)$ & $(0.024)$ & $(0.025)$ \\
\hline & {$[0.001]$} & {$[0.001]$} & {$[<0.001]$} & {$[<0.001]$} & {$[<0.001]$} \\
\hline PDUFA-II*TIME & -0.0367 & -0.0392 & -0.0872 & -0.0939 & -0.0869 \\
\hline & $(0.015)$ & $(0.017)$ & $(0.017)$ & $(0.016)$ & $(0.016)$ \\
\hline & {$[0.0178]$} & {$[0.020]$} & {$[<0.001]$} & {$[<0.001]$} & {$[<0.001]$} \\
\hline NOCOM\% & & 0.0321 & & & \\
\hline & & $(0.086)$ & & & \\
\hline & & {$[0.710]$} & & & \\
\hline LNNOCOM & & & 00573 & & \\
\hline LNNOCOM & & & $\begin{array}{l}0.05 / 3 \\
(0.009)\end{array}$ & & \\
\hline & & & {$[<0.001]$} & & \\
\hline EVERNOCOM & & & & 0.3928 & \\
\hline & & & & $(0.050)$ & \\
\hline & & & & {$[<0.001]$} & \\
\hline & & & & & \\
\hline NOABSENCE & & & & & -0.2445 \\
\hline & & & & & $(0.064)$ \\
\hline & & & & & {$[<0.001]$} \\
\hline LNNOCOMX & & & & & -0.1183 \\
\hline & & & & & $(0.033)$ \\
\hline & & & & & {$[<0.001]$} \\
\hline R-Squared & 0.3925 & 0.3926 & 0.4320 & 0.4468 & 0.4578 \\
\hline
\end{tabular}

Note: Specifications included other covariates as in first three columns of Table 1; parameter estimates on those variables are not reported here. 
Figure 1:

Survival Curves for STANDARD Designated NMES

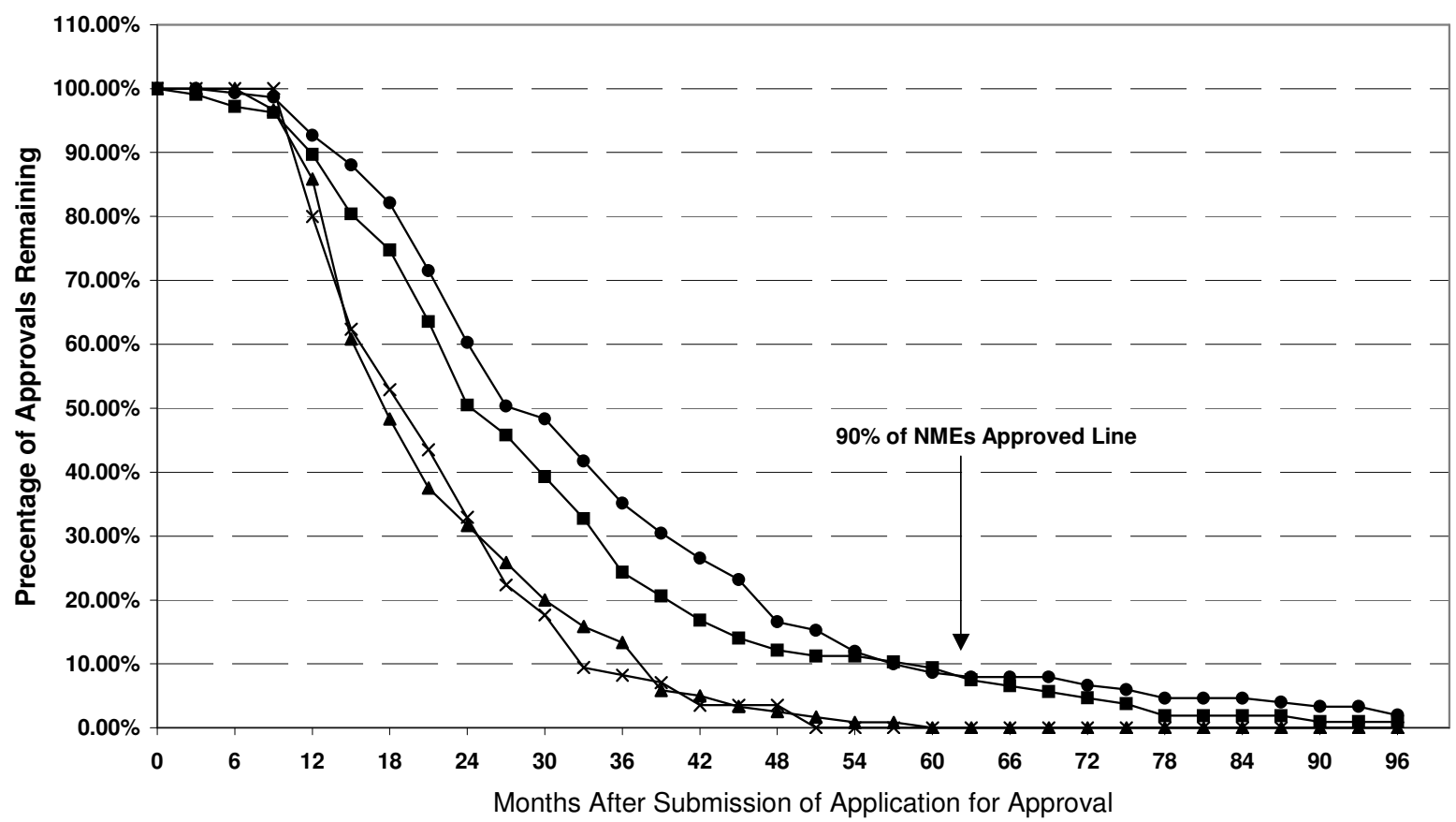

$\bullet-1979-1986 \rightarrow-1986-1992 \rightarrow$ PDUFA I $\rightarrow$ PDUFA II

Figure 2:

Survival Curves for PRIORITY Designated NMES

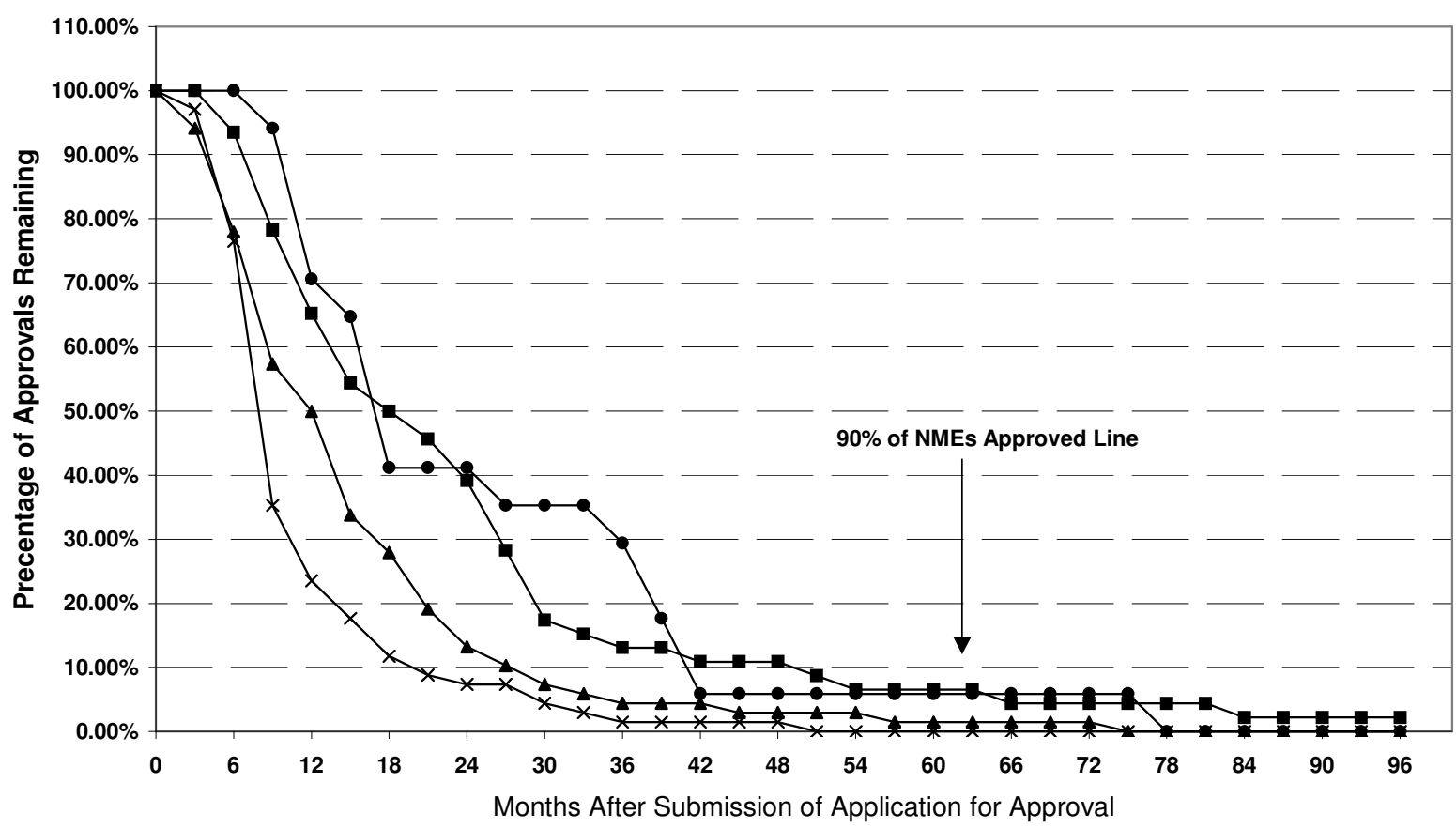

$\rightarrow$ 1979-1986 $\rightarrow-1986-1992 \rightarrow$ PDUFA I $\rightarrow$ PDUFA II 
Figure 3:

Mean and Median Approval Times for All NME NDAs: 1979 to 2002

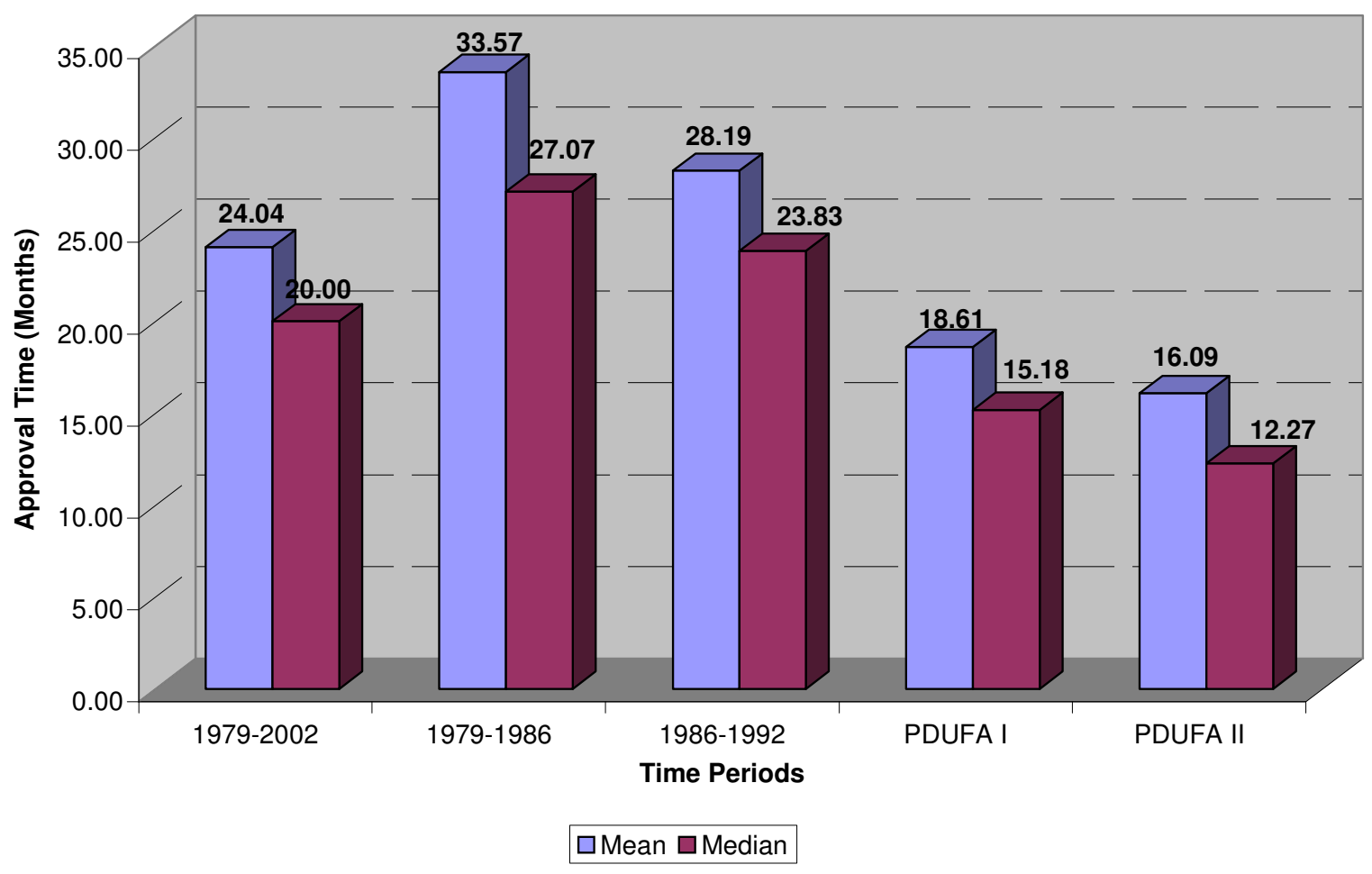


Figure 4:

Predicted NDA/BLA Approval Times with and without PDUFA I/II (Regressors Evaluated at Overall Sample Means)

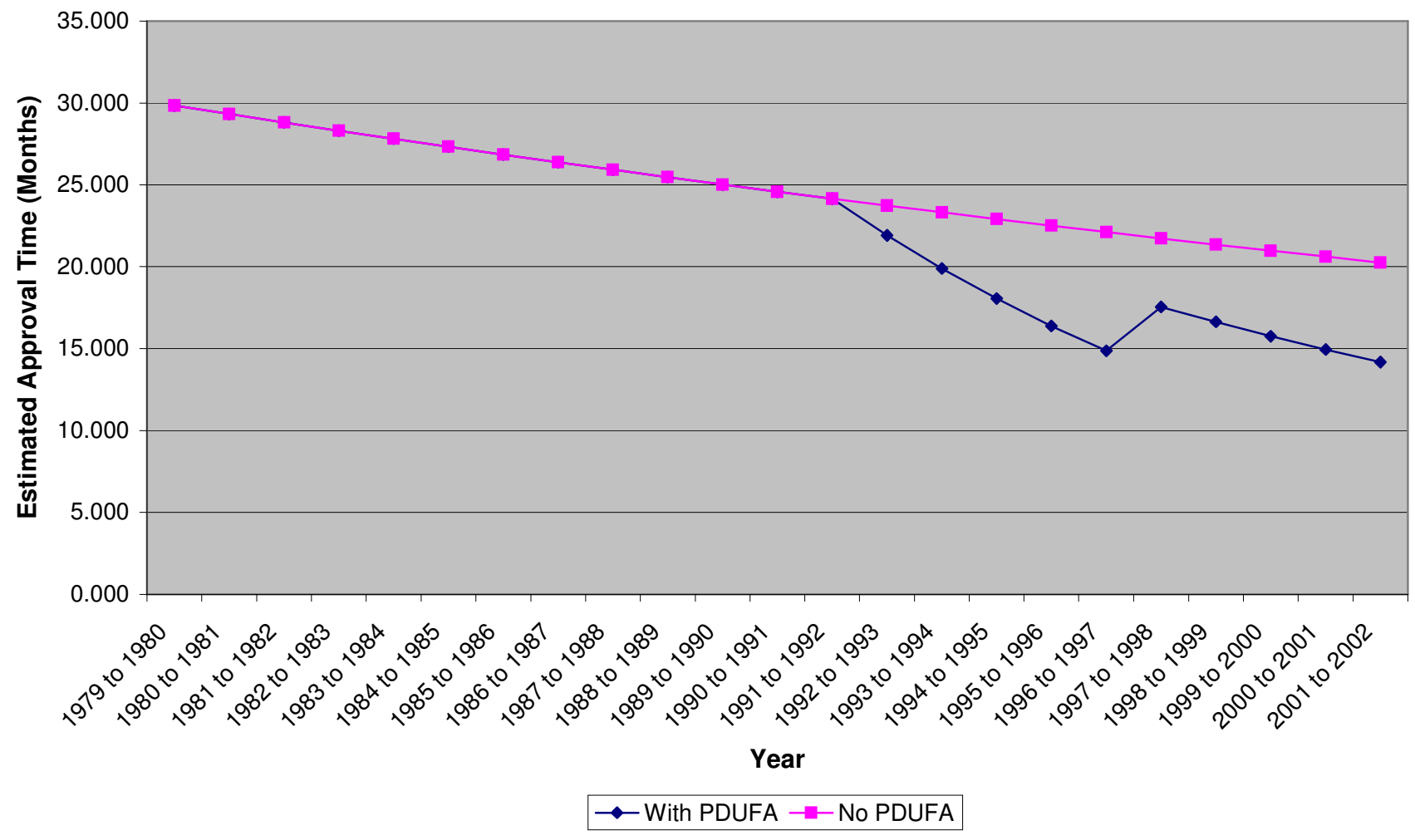




\section{ENDNOTES}

${ }^{1}$ From the FDA Mission Statement, http://www.fda.gov/opacom/morechoises/mission.html.

${ }^{2}$ For discussion and references, see Michael Dickson and Jean Paul Gagnon [2004], "Key Factors in the Rising Cost of New Drug Discovery and Development”, Nature Reviews: Drug Discovery, Vol. 3, May, 417-429. An early critique of the FDA is that by Samuel Peltzman [1974], Regulation of Pharmaceutical Innovation: The 1962 Amendments, Washington DC: American Enterprise Institute for Public Policy Research.

${ }^{3}$ Ernst R. Berndt, Adrian Gottschalk, Tomas Philipson and Matthew Strobeck [2004], "PDUFA: Towards An Economic Analysis”, draft manuscript, MIT Sloan School of Management, October.

${ }^{4}$ U.S. Food and Drug Administration, FY 2002 PDUFA Financial Report [2003], p. 6, and p. 9.

${ }^{5}$ U.S. Food and Drug Administration [2004], "Prescription Drug User Fees-Overview", U.S. Food and Drug Administration [online] (cited 27 April 2004), http://www.fda.gov.oc/pdufa/overview.html.

${ }^{6}$ U.S. Food and Drug Administration [2004], "PDUFA Reauthorization Performance Goals and Procedures", U.S. Food and Drug Administration [online], (cited 27 April 2004), $<$ http://www.fda.gov/oc/pdufa/PDUFAIIIGoals.html>.

${ }^{7}$ Peltzman [1974], supra. Mary K. Olson [1997], "Firm Characteristics and the Speed of FDA Approval”, Journal of Economics and Management Strategy, Summer, 377-401; Olson [1998], "Pharmaceutical Regulation", in The New Palgrave Dictionary of Economics and the Law, Peter Newman, ed., New York: Stockton Press, 40-45; Olson [2004], "Managing Delegation with User Fees: Reducing Delay in New Drug Review", Journal of Health Politics, Policy and Law, forthcoming; Daniel P. Carpenter [2002], "Groups, the Media, Agency Waiting Costs, and FDA Drug Approval”, American Journal of Political Science, July, 490-505; also see Dickson and Gagnon [2004], supra..

${ }^{8}$ An exception to this is the rare case in which the FDA grants "compassionate use" approval to a drug not yet approved for marketing.

${ }^{9}$ See, for example, Janice M. Reichert [2003], "Trends in Development and Approval Times for New Therapeutics in the United States", Nature Reviews: Drug Discovery, Vol. 2, September, 695-702, and the references cited therein. For an analysis of drug approval times up to 1995, see Joseph A. DiMasi [1996], "A New Look at United States Drug Development and Approval Times", American Journal of Therapeutics, 3:1-11; and DiMasi [1997], "Initiatives to Speed New Drug Development and Regulatory Review: The Impact of FDA-Sponsor Conferences", Drug Information Journal, 31:771-788.

${ }^{10}$ Although we would have preferred to include as a regressor the set of FDA-sponsor conference measures developed by DiMasi [1997] for 166 drugs approved between 1987 and 1995, such data were not available for the full set of 662 drugs considered in this study.

${ }^{11}$ For further discussion of political economy issues involving sponsors and the FDA, see Carpenter [2002], supra; and Carpenter, Michael Chernew, Dean G. Smith and A. Mark Fendrick [2003], "Approval Times for New Drugs: Does the Source of Funding for FDA Staff Matter?", Health Affairs - Web Exclusive, 17 December, W3-618 to W3-624.

${ }^{12}$ US Food and Drug Administration. FDA Commissioners and Their Predecessors. U.S. Food and Drug Administration [online] (cited 27 April 2004) http://www.fda.gov/opacom/morechoices/comm1.html.

${ }^{13}$ See, for example, Reichert [2003] supra, and Dickson and Gagnon [2004] supra.

${ }^{14}$ Ernst R. Berndt, Adrian Gottschalk, Tomas Philipson and Matthew Strobeck [2004], "Assessing the Impact of PDUFA on FDA Drug Approval Times by Therapeutic Class", MIT Sloan School of Management, draft manuscript, October, 
${ }^{15}$ Since LNAPP is the dependent variable and since we have assumed a normally distributed random disturbance term, to create a predicted value in natural (non-logarithmically transformed) units, we exponentiate (predicted value of LNAPP plus $0.5 \mathrm{~s}^{2}$ ), where $\mathrm{s}^{2}$ is the mean squared error from the estimated regression equation.

${ }^{16}$ None of the standard errors in Table 2 increase by more than $15 \%$ when adjusted for heteroskedasticity; but that on the OTHER variable falls about $25 \%$ to 0.114 .

${ }^{17}$ More detailed disaggregation by therapeutic class and further discussions are presented in the MIT Master's theses by Gottschalk and Strobeck. See Adrian H. G. Gottschalk [2004], "Improving the Efficiency of the Later Stages of the Drug Development Process: Survey Results from the Industry, Academia, and the FDA", M.S. thesis submitted to the Harvard-MIT Division of Health Sciences and Technology, May; and Matthew W. Strobeck [2004], "The Drug Development Process: Evaluation of PDUFA I/II and an Investigation into Reducing Drug Development Times", M.S. thesis submitted to the Harvard-MIT Division of Health Sciences and Technology, May.

${ }^{18}$ For a recent discussion, see Simon Frantz [2004], "Another Long Leaderless Period in Store for FDA", Nature Reviews: Drug Discovery, Vol. 3, April 2004, p.289.

${ }^{19}$ See, for example, Christopher Milne and E. M. Bergman [2001], "Fast Track Designation Under the Food and Drug Administration Modernization Act: The Industry Experience," Drug Information Journal, 35:1, 71-83; also see Lisa Piercey [2003], "Life in the Fast Lane", Signals [online], http://signalsmag.com/signalsmag.nsf/CA, May 23, 114.

${ }^{20}$ U.S. Government Accounting Office, Effect of User Fees on Drug Approval Times, Withdrawal, and other Agency Activities, Washington DC: GAO Report 02-958, September [online], htt;://www.gao.gov/new.items/d02958.pdf.

${ }^{21}$ FDA internal analyses and presentation material provided by Ed Hass. 